\title{
Catalytic Asymmetric Generation of (Z)-Disubstituted Allylic
}

\section{Alcohols}

\author{
Luca Salvi, Sang-Jin Jeon, Ethan L. Fisher, Patrick J. Carroll, and Patrick J. Walsh ${ }^{\star}$ \\ Contribution from the P. Roy and Diana T. Vagelos Laboratories, Department of Chemistry, \\ University of Pennsylvania, 231 South 34th Street, Philadelphia, PA 19104-6323
}

\section{Abstract}

A one-pot method for the direct preparation of enantioenriched (Z)-disubstituted allylic alcohols is introduced. Hydroboration of 1-halo-1-alkynes with dicyclohexylborane, reaction with $t$-BuLi, and transmetallation with dialkylzinc reagents generates $(Z)$-disubstituted vinylzinc intermediates. In situ reaction of these reagents with aldehydes in the presence of a catalyst derived from (-)-MIB generates (Z)-disubstituted allylic alcohols. It was found that the resulting allylic alcohols were racemic, most likely due to a rapid addition reaction promoted by $\mathrm{LiX}(\mathrm{X}=\mathrm{Br}$ and $\mathrm{Cl})$. To suppress the $\mathrm{LiX}$ promoted reaction, a series of inhibitors was screened. It was found that 20-30 mol \% tetraethylethylene diamine (TEEDA) inhibited $\mathrm{LiCl}$ without inhibiting the chiral zinc-based Lewis acid. In this fashion, (Z)-disubstituted allylic alcohols were obtained with up to $98 \%$ ee. The asymmetric ( $Z$ )-vinylation could be coupled with tandem diastereoselective epoxidation reactions to provide epoxy alcohols and allylic epoxy alcohols with up to three contiguous stereogenic centers, enabling the rapid construction of complex building blocks with high levels of enantio- and diastereoselectivity.

\section{Introduction}

Enantioenriched allylic alcohols are among the most commonly used chiral building blocks and have been widely applied in natural and non-natural product synthesis. ${ }^{1-4}$ They are also precursors to enantioenriched epoxy alcohols, $5-7,4,1,8-10$ allylic amines, ${ }^{11-14} \alpha$ - and $\beta$ amino acids, ${ }^{13,15}$ and cyclopropyl alcohols. ${ }^{16-19}$ Enantioenriched allylic alcohols are often isolated from kinetic resolution (KR) with the Sharpless-Katsuki asymmetric epoxidation catalyst. ${ }^{5-7,4}$ Although $(E)$-allylic alcohols are excellent substrates for the KR, (Z)disubstituted allylic alcohols are not (Scheme 1) ${ }^{5-7,4}$ Other drawbacks to the KR include the need to separate the desired allylic alcohol from the epoxy alcohol product and a maximum yield of $50 \% .20$

More efficient methods to prepare allylic alcohols include asymmetric vinylation of aldehydes $21-25,13,15,8-10,26-28$ or ketones ${ }^{29,30}$ (Scheme 2 ) and reductive coupling of alkynes and carbonyl compounds. ${ }^{31-36}$ These methods simultaneously generate the C-C bond and a stereogenic center in a single step. Almost all vinylation methods are initiated by hydrometallation of terminal alkynes, via hydroboration $37,21-23$ or hydrozirconation, 38,24 , 25 followed by addition of the resulting $(E)$-vinyl organometallic reagents to aldehydes or ketones to furnish $(E)$-allylic alcohols (Scheme 2). Similar methods to prepare (Z)-allylic alcohols would require trans hydrometallations, which are rarely observed. ${ }^{39,40}$ One direct $(Z)$-vinylation of aldehydes has been reported involving the Nozaki-Hiyama-Kishi reaction with (Z)-vinyl halides. The only (Z)-vinyl halide in this study, however, underwent addition with $30 \%$ enantioselectivity. ${ }^{41}$ 
Progress toward the generation of enantioenriched ( $Z$ )-dienyl alcohols has recently been reported by the Krische group ${ }^{36}$ employing acetylene, hydrogen, and an aldehyde or $\alpha$ ketoester in the presence of a rhodium catalyst (Scheme 3). Preliminary studies directed toward enantioselective versions of this dienylation reaction are promising.

We have been interested in the development and applications of vinyl organometallic reagents that enable the construction of di- and trisubstituted olefins and allylic alcohols. $13,15,8,9,30$, $29,10,19,42$ Synthons for these species are shown in Figure 1. The synthon for the $(E)$ disubstituted vinyl groups represented in Scheme 2 (A, Figure 1) is readily derived from hydrometallation of terminal alkynes. A synthon for a $(Z)$-di- or trisubstituted vinyl group (Figure 1, B), on the other hand, contains two reactive positions, a nucleophilic site cis to $\mathrm{R}^{1}$ and an electrophilic site trans to $\mathrm{R}^{1}{ }^{43-45}$ For generation of $(Z)$-disubstituted allylic alcohols, the nucleophilic reagent added to the electrophillic site is a hydride. In the development of reagents for synthon $\mathbf{B}$, it is critical that the double bond stereochemistry be preserved during bond-forming processes.

We recently reported a one-pot stereospecific method for the synthesis of (Z)-disubstituted allylic alcohols based on synthon B (Scheme 4). ${ }^{46}$ Initial hydroboration of 1-bromo-1-alkynes with dicyclohexylborane furnishes 1-bromo-1-alkenylboranes regioselectively. It is known that nucleophiles react with 1-bromo-1-alkenylboron derivatives via addition of the nucleophile to the open coordination site on boron followed by migration of the nucleophile 47,48 or a boron alkyl to the vinylic position with inversion at the vinylic center. 49-51,48,52,42 In our investigations we chose to use $t$-BuLi, which had been shown to be an excellent hydride source by Molander ${ }^{48}$ for the formation of (Z)-vinylboranes. Vinylboranes are fairly unreactive toward carbonyl additions. We envisioned that the ( $Z$ )-vinyl group would undergo boron to zinc transmetallation with dialkylzinc reagents to generate more reactive vinylzinc reagents. In fact, the increased reactivity of the vinylzinc reagent enabled additions to aldehydes to proceed smoothly to generate $(Z)$-allylic alcohols. ${ }^{46}$ Using this method, a variety of racemic $(Z)$-allylic alcohols were prepared in high yields. Additions of $(Z)$-vinyl groups to enantioenriched protected $\alpha$ - and $\beta$-hydroxy aldehydes resulted in formation of $(Z)$ allylic alcohols with high diastereoselectivity. ${ }^{46}$ Unfortunately, attempts at enantioselective versions of this transformation afforded only racemic products.

We now disclose the first general and direct catalytic asymmetric synthesis of (Z)-allylic alcohols. The application of this method to the one-pot preparation of highly functionalized epoxy alcohols and allylic epoxy alcohols is also demonstrated. These reactions lead to a rapid increase in molecular complexity and enable the synthesis of highly functionalized chiral building blocks.

\section{Experimental Section}

\section{General Methods}

All reactions were performed under a nitrogen atmosphere with oven-dried glassware using standard Schlenk or vacuum line techniques. The progress of all reactions was monitored by thin-layer chromatography which was performed on Whatman precoated silica gel $60 \mathrm{~K} 6 \mathrm{~F}$ plates and visualized by ultra-violet light or by staining with phosphomolybdic acid. $t$-BuOMe was distilled from $\mathrm{Na}$ /benzophenone and hexanes was dried through alumina columns. Tetraethylethylene diamine (TEEDA) was distilled and stored under nitrogen. The ${ }^{1} \mathrm{H}$ NMR and ${ }^{13} \mathrm{C}\left\{{ }^{1} \mathrm{H}\right\}$ NMR spectra were obtained on a Brüker AM-500 Fourier transform NMR spectrometer at 500 and $125 \mathrm{MHz}$, respectively. ${ }^{1} \mathrm{H}$ NMR spectra were referenced to tetramethylsilane in $\mathrm{CDCl}_{3}$ or residual protonated solvent; ${ }^{13} \mathrm{C}\left\{{ }^{1} \mathrm{H}\right\} \mathrm{NMR}$ spectra were referenced to residual solvent. Analysis of enantiomeric excess was performed using a HewlettPackard 1100 Series HPLC and a chiral column specific for each compound. The optical 
rotations were recorded using a JASCO DIP-370. Infrared spectra were obtained using a Perkin-Elmer Spectrum 100 series spectrometer. All reagents were purchased from Aldrich or Acros unless otherwise described. 1-Bromo-1-alkynes ${ }^{53}$ and 1-chloro-1-alkynes ${ }^{54}$ were made according to known procedure. All commercially available aldehyde substrates were distilled prior to use. Silica gel (Silicaflash P60 40-63 $\mu \mathrm{m}$, Silicycle) was used for air-flashed chromatography and deactivated silica gel was prepared by addition of $15 \mathrm{~mL} \mathrm{NEt}_{3}$ to $1 \mathrm{~L}$ of silica gel. Complete experimental procedures and characterization are located in the Supporting Information.

\section{Caution}

Dialkylzinc reagents and $t$-BuLi are pyrophoric. Care must be used when handling solutions of these reagents.

\section{Synthesis of (Z)-Disubstituted Allylic Alcohols}

\section{Preparation of (Z)-5-(tert-butyl-diphenyl-silanyloxy)-1-phenyl-pent-2-en-1-ol (3ac)}

Dicyclohexylborane ( $88 \mathrm{mg}, 0.5 \mathrm{mmol}$ ) was weighed into a Schlenk flask under nitrogen and dry $t$-BuOMe (1 mL) was added. tert-Butyl-(4-chloro-but-3-ynyloxy)-diphenyl-silane (1a, 160 $\mu \mathrm{L}, 0.5 \mathrm{mmol}$ ) was then added slowly to the reaction mixture at $0{ }^{\circ} \mathrm{C}$. After $15 \mathrm{~min}$, the solution was warmed to room temperature and stirred for $45 \mathrm{~min}$, resulting in a clear solution. $t$-BuLi ( $0.37 \mathrm{~mL}, 0.55 \mathrm{mmol}, 1.5 \mathrm{M}$ pentane solution) was added dropwise at $-78{ }^{\circ} \mathrm{C}$ and stirred for $60 \mathrm{~min}$ before the solution was warmed to room temperature and stirred for $60 \mathrm{~min}$. During this time, a precipitate, presumably $\mathrm{LiCl}$, formed. Diethylzinc $(0.28 \mathrm{~mL}, 0.55 \mathrm{mmol}, 2 \mathrm{M}$ hexanes solution) was slowly added to the reaction mixture at $-78^{\circ} \mathrm{C}$ and the solution was stirred for $20 \mathrm{~min}$. Next, TEEDA $(14 \mu \mathrm{L}, 0.066 \mathrm{mmol})$ and hexanes $(4 \mathrm{~mL})$ were added at -78 ${ }^{\circ} \mathrm{C}$, the solution was warmed to $0{ }^{\circ} \mathrm{C}$, and (-)-MIB $(166 \mu \mathrm{L}, 0.017 \mathrm{mmol})$ and benzaldehyde (34 $\mu \mathrm{L}, 0.33 \mathrm{mmol}$ ) were added. The reaction was then slowly warmed to room temperature and stirred for 16 hours. After the reaction was complete by TLC analysis, the mixture was diluted with $3 \mathrm{~mL}$ hexanes and quenched with $\mathrm{H}_{2} \mathrm{O}$. The organic layer was separated, and the aqueous solution was extracted with EtOAc $(2 \times 10 \mathrm{~mL})$. The combined organic layer was dried over $\mathrm{MgSO}_{4}$, filtered, and the solvent was removed under reduced pressure. The crude product was purified by column chromatography on silica gel (hexanes:EtOAc, 95:5) to give 3ac ( $83.8 \mathrm{mg}, 61 \%$ yield) as an oil. The ee was determined by HPLC equipped with a Chiralcel AD-H column (hexanes:2-propanol, 99:1, flow rate $=0.5 \mathrm{~mL} / \mathrm{min}$ ), $\mathrm{t}_{\mathrm{r}}(1)=38.2 \mathrm{~min}, \mathrm{t}_{\mathrm{r}}(2)=$ $44.6 \mathrm{~min},[\alpha]_{\mathrm{D}}{ }^{20}=+131.11\left(c=0.001, \mathrm{CHCl}_{3}, 95 \% \mathrm{ee}\right) ;{ }^{1} \mathrm{H} \mathrm{NMR}\left(\mathrm{CDCl}_{3}, 500 \mathrm{MHz}\right): \delta 1.12$ (s, 9H), 2,20 (br, 1H), 2.45-2.51 (m, 1H), 2.58-2.65 (m, 1H), 3.73-3.80 (m, 2H), 5.50-5.51 (dd, $J=1.9,8.0 \mathrm{~Hz}, 1 \mathrm{H}), 5.60-5.67(\mathrm{dt}, J=7.8,11.2 \mathrm{~Hz}, 1 \mathrm{H}), 5.77-5.81(\mathrm{dd}, J=8.5,10.9 \mathrm{~Hz}$, 1H), 7.40 (m 10H), $7.71(\mathrm{~m}, 5 \mathrm{H}) \mathrm{ppm} ;{ }^{13} \mathrm{C}\left\{{ }^{1} \mathrm{H}\right\} \mathrm{NMR}\left(\mathrm{CDCl}_{3}, 125 \mathrm{MHz}\right): \delta$ 19.4, 27.1, 31.4, $63.5,69.9,126.1,127.6,127.9,128.7,128.8,129.9,133.8,134.5,135.8,143.7$ ppm; IR (neat): 3369, 3069, 2931, 1958, 1890, 1824, 1656, 1589, 1472, 1427, $1389 \mathrm{~cm}^{-1}$; HRMS calcd for $\mathrm{C}_{27} \mathrm{H}_{32} \mathrm{NaO}_{2} \mathrm{Si}(\mathrm{M}+\mathrm{Na})^{+}:$439.2069, found 439.2054.

The number of peaks in the ${ }^{13} \mathrm{C}$ NMR reflects the fact that the two phenyl groups attached to silicon are too far from the stereocenter to be seen as diastereotopic, thus only 4 signals are present for those two phenyl groups.

\section{Asymmetric Addition/Diastereoselective Epoxidation Reactions Preparation of [3-(4-chloro-butyl)-oxiranyl]-phenyl-methanol (4cc)}

Dicyclohexylborane ( $88 \mathrm{mg}, 0.5 \mathrm{mmol}$ ) was weighed into a Schlenk flask under nitrogen and dry $t$-BuOMe $(1 \mathrm{~mL})$ was added. 1,6-Dichloro-hex-1-yne $(66 \mu \mathrm{L}, 0.5 \mathrm{mmol})$ was then added slowly to the reaction mixture at $0{ }^{\circ} \mathrm{C}$. After $15 \mathrm{~min}$, the solution was warmed to room 
temperature and stirred for $45 \mathrm{~min} . t$ - $\mathrm{BuLi}(0.37 \mathrm{~mL}, 0.55 \mathrm{mmol}, 1.5 \mathrm{M}$ pentane solution) was added dropwise at $-78^{\circ} \mathrm{C}$ and the solution stirred for $60 \mathrm{~min}$. The reaction mixture was then warmed to room temperature and stirred for an additional $60 \mathrm{~min}$. During this time, a white precipitate formed. Diethylzinc $(0.28 \mathrm{~mL}, 0.55 \mathrm{mmol}, 2 \mathrm{M}$ hexanes solution) was slowly added to the reaction mixture at $-78{ }^{\circ} \mathrm{C}$ and the solution stirred for $20 \mathrm{~min}$. Addition of TEEDA (14 $\mu \mathrm{L}, 0.066 \mathrm{mmol})$ and hexanes $(4 \mathrm{~mL})$ was performed at $-78^{\circ} \mathrm{C}$ and the solution warmed to 0 ${ }^{\circ} \mathrm{C}$. Addition of (-)-MIB ( $\left.166 \mu \mathrm{L}, 0.017 \mathrm{mmol}\right)$ was followed by addition of benzaldehyde (34 $\mu \mathrm{L}, 0.332 \mathrm{mmol})$. The reaction mixture was then slowly warmed to room temperature and stirred for 16 hours. After the reaction was complete by TLC analysis, the temperature was brought to $-20{ }^{\circ} \mathrm{C}$ and $\mathrm{ZnEt}_{2}(0.28 \mathrm{~mL}, 0.55 \mathrm{mmol}, 2 \mathrm{M}$ solution in hexanes) was added. The reaction was stirred for $30 \mathrm{~min}$ and then TBHP (tert-butylhydroperoxide, $0.30 \mathrm{~mL}, 1.68 \mathrm{mmol}$, $5.5 \mathrm{M}$ solution in decane) was added. After an additional $30 \mathrm{~min}$ at $-20^{\circ} \mathrm{C}, \mathrm{Ti}(\mathrm{O} i-\mathrm{Pr})_{4}(48$ $\mu \mathrm{L}, 0.067 \mathrm{mmol}, 1.4 \mathrm{M}$ solution in hexanes) was added and the mixture stirred until the allylic alkoxide had been consumed (TLC, $\sim 16 \mathrm{~h}$ ). The reaction mixture was then quenched with 2 $\mathrm{mL}$ saturated aq. $\mathrm{NH}_{4} \mathrm{Cl}$, stirred for $30 \mathrm{~min}$ at room temperature, and quenched with an aqueous solution of $\mathrm{Na}_{2} \mathrm{~S}_{2} \mathrm{O}_{3}$. The organic and aqueous layers were separated, and the aqueous layer was extracted with diethyl ether $(3 \times 5 \mathrm{~mL})$. The combined organic layers were then washed with $5 \mathrm{~mL}$ brine, $5 \mathrm{~mL} \mathrm{H}_{2} \mathrm{O}$, dried over $\mathrm{MgSO}_{4}$, and filtered. The filtrate was collected, concentrated in vacuo, and the crude product was purified by column chromatography on deactivated silica gel (hexanes:EtOAc, 90:10) to give $4 \mathbf{c c}(53.6 \mathrm{mg}, 67 \%$ yield) as an oil. $\left[\mathrm{a}_{\mathrm{D}}{ }^{20}=+56.03\left(c=0.041, \mathrm{CHCl}_{3}\right) ;{ }^{1} \mathrm{H} \mathrm{NMR}\left(\mathrm{CDCl}_{3}, 500 \mathrm{MHz}\right): \delta 1.64(\mathrm{~m}, 6 \mathrm{H}), 2.46(\mathrm{~d}\right.$, $J=2.9 \mathrm{~Hz}, 1 \mathrm{H}), 3.1(\mathrm{~m}, 1 \mathrm{H}), 3.20(\mathrm{dd}, J=4.4,8.4 \mathrm{~Hz}, 1 \mathrm{H}), 3.56(\mathrm{t}, J=6.8 \mathrm{~Hz}, 2 \mathrm{H}), 4.58(\mathrm{dd}$, $J=2.8,8.0 \mathrm{~Hz}, 1 \mathrm{H}), 7.31(\mathrm{~m}, 5 \mathrm{H}) \mathrm{ppm} ;{ }^{13} \mathrm{C}\left\{{ }^{1} \mathrm{H}\right\} \mathrm{NMR}\left(\mathrm{CDCl}_{3}, 125 \mathrm{MHz}\right): \delta 24.5,28.0,32.3$, 44.9, 58.3, 61.4 , 72.5, 126.4, 128.6, 129.0, 140.1 ppm; IR (neat): 3419, 3062, 3031, 2955, 2866, $1807,1604,1492,1454,1278,1195,1040 \mathrm{~cm}^{-1}$; HRMS calcd for $\mathrm{C}_{13} \mathrm{H}_{16} \mathrm{OCl}(\mathrm{M}-\mathrm{OH})^{+}$: 223.08897, found 223.08883. Analysis of diastereomeric ratio was performed by ${ }^{1} \mathrm{H}$ NMR spectroscopy.

\section{Results and Discussion}

When our $(Z)$-vinylation of aldehydes (Scheme 4) was conducted in the presence of the amino alcohol-based catalyst derived from (-)-MIB, 55,56 the (Z)-allylic alcohol product was isolated in good yields, but the product was found to be racemic. This was surprising because the zincbased catalyst derived from (-)-MIB is one of the most efficient and enantioselective amino alcohol-based catalysts known for carbonyl additions. The absence of enantioselectivity was attributed to the rapid addition reaction promoted by the liberated Lewis acid byproduct, $\mathrm{LiBr}$ (Scheme 4). Rather than attempt to remove the $\mathrm{LiBr}$ byproduct by filtration ${ }^{57}$ or centrifugation, 58 which would be impractical on large scale, we decided to deactivate it.

Our first attempts to inhibit the salt byproduct were based on observations reported by Bolm. In a study involving the addition of $\mathrm{Ph}_{2} \mathrm{Zn}$ to aldehydes, Bolm and coworkers emphasized the beneficial effect of dimethoxy poly(ethyleneglycol) (DiMPEG) on the reaction enantioselectivity. ${ }^{57}$ They proposed that DiMPEG suppressed reactions catalyzed by trace achiral Lewis acids, including $\mathrm{LiBr}$, allowing most of the arylation reaction to proceed via the ligand accelerated ${ }^{59}$ Lewis acid catalyzed pathway. 60

To suppress the LiBr-promoted vinyl addition to aldehydes, we employed DiMPEG as inhibitor (Scheme 5). Addition of 5-7 mol \% DiMPEG (MW $2000 \mathrm{~g} / \mathrm{mol}$ ) proved most effective, with enantioselectivities in the (Z)-vinylation reaching 86\% (Table 1, entries 1-4). Although this result was exciting and promising, we found that the reactions were very sensitive to the mol $\%$ DiMPEG and enantioselectivities were difficult to reproduce. Tetraglyme was used as a DiMPEG analog but was significantly less effective at inhibiting LiBr (Table 1, entries 5-7). After significant effort to identify reliable polyether inhibitors, this strategy was abandoned. 
Instead, we turned to a diamine inhibitor that we had successfully used to solve a similar problem in our development of the first highly enantioselective one-pot asymmetric synthesis of enantioenriched diarylmethanols beginning from aryl bromides (Scheme 6). ${ }^{61}$ Like the vinylation in Scheme 4, initial attempts at the asymmetric arylation reactions also resulted in formation of essentially racemic products. In the transmetallation reactions used to generate the aryl group donor, $\mathrm{Ar}-\mathrm{Zn}(n$-Bu), over 4 equiv $\mathrm{LiCl}$ were formed. As seen in the vinylation reactions, this Lewis acidic byproduct was significantly faster at promoting the aryl addition to provide diarylmethanols than the chiral amino alcohol-based catalyst, resulting in formation of racemic product. Another possible mechanism for the $\mathrm{LiCl}$ accelerated addition to aldehydes is via formation of a more reactive zincate by interaction of the $\mathrm{LiCl}$ with the organozinc to generate $\mathrm{R}_{2} \mathrm{ZnCl}^{-} \mathrm{Li}^{+} .62,45$ Although this mechanism cannot be ruled out at this time, we favor the Lewis acid activation of the aldehyde on the basis of the results in the following paragraph.

The key to our successful development of an asymmetric arylation system was inhibition of the $\mathrm{LiCl}$ byproduct with tetraethylethylene diamine (TEEDA). The diamine is believed to chelate the $\mathrm{LiCl}$ to form a chloride-bridged dimer [(TEEDA) $\mathrm{LiCl}_{2}$ that is coordinatively saturated and catalytically inactive (Figure 2). ${ }^{63,64}$ Using this technique, the racemic background reaction was completely suppressed, resulting in formation of diarylmethanols with enantioselectivities as high as $97 \%$.

When our diamine-based strategy in Scheme 6 was applied to the synthesis of (Z)-allylic alcohols in Scheme 5, enantioselectivities peaked at $10 \%$ under our best conditions (Table 1, entries 8 and 9). These results suggested to us that inhibition of $\mathrm{LiBr}$ would be significantly different from inhibition of $\mathrm{LiCl}$. We speculate that the bromide analogs of [(TEEDA)LiCl $]_{n}$ (Figure 2) dissociate more readily to generate an open coordination site capable of aldehyde activation. Rather than search for a new inhibitor for $\mathrm{LiBr}$, we chose to examine 1-chloro-1alkynes in this process, which would generate $\mathrm{LiCl}$.

Examination of 1-chloro-1-alkynes was approached in a similar fashion to the optimization of 1-bromo-1-alkynes. When 1-bromo-1-alkynes were employed in our previous study 46 (Scheme 4), we found it necessary to perform the addition of $t$-BuLi in THF. A solvent switch was then needed, because the vinylzinc addition proceeds in low yield in THF. Using the 1chloro-1-alkynes, however, the entire reaction could be performed in $t$-BuOMe solvent, without the need to switch solvents. Hydroboration of 1-chloro-1-alkynes (1.5 equiv) with $\mathrm{Cy}_{2} \mathrm{BH}$ (1.5 equiv) proceed in $1 \mathrm{~h}$ at $0{ }^{\circ} \mathrm{C}-$ room temperature with excellent regioselectivity. Reaction of the resulting 1-chloro-1-vinylborane with $t$-BuLi (1.65 equiv) occurred with inversion at the vinylic center, generating the $(Z)$-vinylborane. Transmetallation with diethylzinc (1.65 equiv) and addition to an aldehyde (1 equiv) in the presence of the (-)-MIBbased catalyst provided the racemic allylic alcohol. Repeating the sequence with the addition of increasing amounts of TEEDA resulted in the formation of enantioenriched $(Z)$-allylic alcohol products (Table 1, entries $10-16$ ). The highest enantioselectivities were obtained with 20-30 mol \% TEEDA. Further increases in the mol \% diamine caused a decrease in both enantioselectivity and yield. This observation is likely due to inhibition of the chiral zinc-based catalyst by the diamine, allowing the uncatalyzed background reaction to become competitive with the catalyzed addition, eroding the product ee. Note that less than an equivalent of diamine per equivalent of $\mathrm{LiCl}$ is needed. Much of the $\mathrm{LiCl}$ precipitates from solution and is not active in promoting the addition reaction.

With the optimized conditions in Table 1, we examined the scope of the asymmetric vinylation (Table 2). Employing 20-30 mol \% TEEDA, a variety of 1-chloro-1-alkynes and aldehydes underwent the addition in good yields (61-93\%, based on aldehyde as the limiting reagent) and good to excellent enantioselectivities (75-98\%). 1-Chloro-1-alkynes bearing a TBDPS protected alcohol (entries 1-6), alkyl (entries 7 and 8), chloro alkyl (entries $9-16$ ), or phenyl 
groups (entries 17 and 18) were successfully employed in the asymmetric vinylation reaction. Although aliphatic aldehydes with $\alpha$-branching underwent addition with high enantioselectivity ( $84-90 \%$, entries 1,8 , and 11), $\beta$-branched isovaleraldehyde was a more challenging substrate, undergoing addition with $76 \%$ enantioselectivity (entry 2). Likewise, dihydrocinnamaldehyde underwent addition with $75 \%$ enantioselectivity (entry 6). $\alpha, \beta$ Unsaturated aldehydes reacted to form dienols with 88-94\% enantioselectivity (entries 15 and 16). Aryl aldehydes were also good substrates for the vinylation reaction, providing benzylic alcohols with enantioselectivities between 86 and 98\%. The electron withdrawing trifluoromethyl benzaldehyde exhibited the lowest enantioselectivity of this class of substrates, possibly due to an earlier transition state with less bond formation and reduced steric bias (entry 12). The heterocyclic aldehyde, 2-thiophene carboxaldehyde, proved to be an excellent substrate for (Z)-vinylations proceeding in 92-94\% enantioselectivity (entries 5, 10, and 18). This route to thiophene containing allylic alcohols avoids potential problems with catalyst poisoning that can arise in hydrogenation of thiophene-containing propargylic alcohols. ${ }^{65-}$

70 Beyond catalyst poisoning, over reduction and contamination with the undesired $(E)$-isomer have been reported to be problematic. ${ }^{70}$ Similarly, the alkyne-bearing product in entry 4 would be difficult to prepare by selective Lindlar reduction.

Important in the development of practical methods with potential utility in target oriented synthesis is the evaluation of scalability. With this in mind, we examined the substrate combination in entry 14 using $5.0 \mathrm{mmol}$ of the aldehyde. The desired $(Z)$-allylic alcohol was obtained in $79 \%$ yield at this scale with $96 \%$ ee. The high yield and enantioselectivity in this reaction bode well for large-scale applications of these asymmetric addition reactions.

Having developed a viable method for the catalytic asymmetric synthesis of (Z)-disubstituted allylic alcohols, we wanted to briefly examine the potential application of this process in tandem addition/epoxidation reactions. We recently developed methods for tandem asymmetric alkylation of enones 71,72 and enals $9,8,10$ followed by diastereoselective epoxidation of the resulting allylic alkoxide to provide epoxy alcohols with up to three contiguous stereogenic centers. The oxidant in the epoxidation was a zinc peroxide generated upon reaction of either TBHP or dioxygen with dialkylzinc reagents. Adaptation of our addition/epoxidation method to the (Z)-vinylation reagents is illustrated in Scheme 7. Initially we were concerned that the reaction would be hampered by the presence of the TEEDA, due to its known coordination to titanium alkoxides ${ }^{73}$ or oxidation to the $N$-oxide, as was observed in the KR of racemic $\beta$-amino alcohols by Sharpless. ${ }^{74}$ Fortunately, these side reactions did not interfere with the epoxidation.

The generation of the allylic zinc alkoxide was performed as outlined in Scheme 5. Rather than addition of water to quench the allylic alkoxide intermediate, however, 2 equiv of diethylzinc were injected into the flask. Dropwise addition of a $5.5 \mathrm{M}$ solution of TBHP in decane was then followed by titanium tetraisopropoxide $(20 \mathrm{~mol} \%)$. The epoxidations were conducted at $-20{ }^{\circ} \mathrm{C}$ and stirred for $24 \mathrm{~h}$ before workup. The crude epoxy alcohols were chromatographed and isolated in $52-67 \%$ yield with excellent dr (19:1 in each case, Scheme 7).

To aid in the assignment of the relative stereochemistry in the epoxy alcohol products in Scheme 7, we examined the diastereoselective epoxidation of an isolated allylic alcohol with the complementary epoxidizing agents $m \mathrm{CPBA}$ and $\mathrm{VO}(\mathrm{acac})_{2} / \mathrm{TBHP}$ (Scheme 8). It is well known that $\mathrm{VO}(\mathrm{acac})_{2} / \mathrm{TBHP}$ exhibits high diastereoselectivity with allylic alcohols that possess $A^{1,2}$ strain in one of the diastereomeric epoxidation transition states. In contrast, $m$ CPBA is known to epoxidized with high diastereoselectivity when allylic alcohols lead to $\mathrm{A}^{1,3}$ strain in one of the diastereomeric epoxidation transition states. ${ }^{3}$ Subjecting the preformed allylic alcohol in Scheme 8 to the typical epoxidation conditions with $\operatorname{VO}(\mathrm{acac})_{2} /$ TBHP and $m$ CPBA afforded the epoxy alcohols with 2.5:1 and 10:1 dr, respectively. The 
$m$ CPBA epoxidation resulted in high stereoselectivity and formed the same diastereomer as our one-pot addition/epoxidation procedure. This observation indicates that the syn diastereomer is formed in the tandem reaction, as shown in Scheme 7. Furthermore, the stereochemistry of $\mathbf{4 d \mathbf { c }}$ was assigned by derivatization with (-)-camphanic acid chloride to afford the expected ester, which was characterized by X-ray crystallography (see Supporting Information).

Having demonstrated that the epoxidation of the (Z)-allylic alkoxide could be performed in the tandem addition/epoxidation reaction, we wanted to explore the preferential epoxidation of a more substituted double bond in the presence of the (Z)-vinyl group. Thus, addition of the $(Z)$-vinylzinc reagent to cyclohexenecarboxaldehyde generated the intermediate dienyl alkoxide, which was subsequently exposed to zinc peroxide and titanium tetraisopropoxide to furnish the allylic epoxy alcohol derived from oxidation of the more electron rich trisubstituted double bond in 52\% yield with 94\% ee and 19:1 dr. The results in Scheme 7 and Scheme 9 highlight a unique feature of this epoxidation system: the ability to perform highly diastereoselective epoxidations with either $\mathrm{A}^{1,2}$ or $\mathrm{A}^{1,3}$ strain in one of the diastereomeric epoxidation transition states. ${ }^{10}$ In contrast, low diastereoselectivity is observed with $m$ CPBA when selectivity is dependent on $\mathrm{A}^{1,2}$ strain in one of the diastereomeric transition states and with $\mathrm{VO}(\mathrm{acac})_{2} / \mathrm{THBP}$ or $\mathrm{Ti}(\mathrm{O} i \text {-Pr })_{4} / \mathrm{TBHP}$ when selectivity is dependent on $\mathrm{A}^{1,3}$ strain. $^{3}$

\section{Outlook and Conclusions}

Herein we have presented the first general highly enantioselective addition of $(Z)$-vinyl groups to aldehydes to afford enantioenriched $(Z)$-allylic alcohols. Employing readily available 1chloro-1-alkynes, hydroboration, addition of $t$-BuLi and transmetallation to zinc affords $(Z)$ vinylzinc intermediates. The resulting $(Z)$-vinylzinc reagents undergo addition to aldehydes with high enantioselectivity in the presence of a zinc-based catalyst derived from MIB. A variety of enantioenriched ( $Z$ )-allylic alcohols can be accessed in this simple one-pot procedure, including some that would be difficult to prepare using Lindlar hydrogenations of enantioenriched propargylic alcohols due to catalyst poisoning or functional group incompatibility.

Furthermore, we have found the conditions for the (Z)-vinylation of aldehydes are compatible with our diastereoselective epoxidation procedure, allowing access to epoxy alcohols and allylic epoxy alcohols with three contiguous stereogenic centers with high ee and dr. Previous methods to prepare such compounds required several synthetic steps and purifications. Using the procedures introduced herein, such compounds can be readily synthesized in a single flask without isolation or purification of intermediates.

Given the rapid increase in molecular complexity with defined stereochemical outcome, we anticipate that these methods will be very useful in enantioselective synthesis.

\section{Supplementary Material}

Refer to Web version on PubMed Central for supplementary material.

\section{Acknowledgements}

We thank the NSF (CHE-065210) and NIH (National Institute of General Medical Sciences GM58101) for partial support of this work. We are also grateful to Akzo Nobel Polymer Chemicals for a gift of dialkylzinc reagents.

\section{References}

1. Katsuki T, Martin VS. Org React 1996:1. 
2. Bonini C, Righib G. Tetrahedron 2002;58:4981-5021.

3. Adam W, Wirth T. Acc Chem Res 1999;32:703-710.

4. Katsuki, T. Comprehensive Asymmetric Catalysis. Jacobsen, EN.; Pfaltz, A.; Yamamoto, H., editors. 2. Springer; Berlin: 1999. p. 621-648.

5. Martín VS, Woodard SS, Katsuki T, Yamada Y, Ikeda M, Sharpless KB. J Am Chem Soc 1981;103:6237-6240.

6. Sharpless KB, Behrens CH, Katsuki T, Lee AWM, Martin VS, Takatani M, Viti SM, Walker FJ, Woodard SS. Pure \& Appl Chem 1983;55:589-604.

7. Gao Y, Klunder JM, Hanson RM, Masamune H, Ko SY, Sharpless KB. J Am Chem Soc 1987;109:5765-5780.

8. Lurain AE, Maestri A, Kelly AR, Carroll PJ, Walsh PJ. J Am Chem Soc 2004;126:13608-13609. [PubMed: 15493905]

9. Lurain AE, Carroll PJ, Walsh PJ. J Org Chem 2005;70:1262-1268. [PubMed: 15704959]

10. Rowley Kelly A, Lurain AE, Walsh PJ. J Am Chem Soc 2005;127:14668-14674. [PubMed: 16231920]

11. Johannsen M, Jørgensen KA. Chem Rev 1998;98:1689-1708. [PubMed: 11848944]

12. Overman LE. J Am Chem Soc 1976;98:2901-2910.

13. Chen YK, Lurain AE, Walsh PJ. J Am Chem Soc 2002;124:12225-12231. [PubMed: 12371863]

14. Chen B, Mapp AK. J Am Chem Soc 2004;126:5364-5365. [PubMed: 15113200]

15. Lurain AE, Walsh PJ. J Am Chem Soc 2003;125:10677-10683. [PubMed: 12940753]

16. Charette AB, Marcoux JF. Synlett 1995:1197-1207.

17. Charette AB, Lebel H. J Org Chem 1995;60:2966-2967.

18. Lebel H, Marcoux JF, Molinaro C, Charette AB. Chem Rev 2003;103:977-1050. [PubMed: 12683775]

19. Kim HY, Lurain AE, García-García P, Carroll PJ, Walsh PJ. J Am Chem Soc 2005;127:13138-13139. [PubMed: 16173729]

20. Keith JM, Larrow JF, Jacobsen EN. Adv Synth Catal 2001;1:5-26.

21. Oppolzer W, Radinov RN. Helv Chim Acta 1992;75:170-173.

22. Oppolzer W, Radinov RN. J Am Chem Soc 1993;115:1593-1594.

23. Oppolzer W, Radinov RN, Brabander JD. Tetrahedron Lett 1995;36:2607-2610.

24. Wipf P, Ribe S. J Org Chem 1998;63:6454-6455.

25. Wipf P, Xu W, Takahashi H, Jahn H, Coish PDG. Pure Appl Chem 1997;69:639-644.

26. Bräse S, Dahmen S, Höfener S, Lauterwasser F, Kreis M, Ziegert RE. Synlett 2004:2647-2669.

27. Richmond ML, Sprout CM, Seto CT. J Org Chem 2005;70:8835-8840. [PubMed: 16238316]

28. Sprout CM, Richmond ML, Seto CT. J Org Chem 2005;70:7408-7417. [PubMed: 16122266]

29. Li H, Walsh PJ. J Am Chem Soc 2004;126:6538-6539. [PubMed: 15161266]

30. Li H, Walsh PJ. J Am Chem Soc 2005;127:8355-8361. [PubMed: 15941269]

31. Miller KM, Huang WS, Jamison TF. J Am Chem Soc 2003;125:3442-3443. [PubMed: 12643701]

32. Miller KM, Jamison TF. Org Lett 2005;7:3077-3080. [PubMed: 15987209]

33. Schmidt F, Rudolph J, Bolm C. Synthesis 2006:3625-3630.

34. Stevens BD, Bungard CJ, Nelson SG. J Org Chem 2006;71:6397-6402. [PubMed: 16901121]

35. Montgomery J. Acc Chem Res 2000;33:467-473. [PubMed: 10913235]

36. Kong JR, Ngai MY, Krische MJ. J Am Chem Soc 2006;128:718-719. [PubMed: 16417351]

37. Srebnik M. Tetrahedron Lett 1991;32:2449-2452.

38. Hart DW, Schwartz J. J Am Chem Soc 1974;96:8115-8116.

39. Ohmura T, Yamamoto Y, Miyaura N. J Am Chem Soc 2000;122:4990-4991.

40. Alexakis A, Duffault JM. Tetrahedron Letters 1988;29:6243-6246.

41. Wan Z-K, Choi H-w, Kang F-A, Nakajima K, Demeke D, Kishi Y. Org Lett 2002;4:4431-4434.

[PubMed: 12465905]

42. Chen YK, Walsh PJ. J Am Chem Soc 2004;126:3702-3703. [PubMed: 15038709] 
43. Kocienski P, Barber C. Pure and Applied Chemistry 1990;62:1933-1940.

44. Kocienski, P.; Klein, W., editors. Wieweg. 1993. p. 203

45. Shibli A, Varghese JP, Knochel P, Marek I. Synlett 2001:818-820.

46. Jeon SJ, Fisher EL, Carroll PJ, Walsh PJ. J Am Chem Soc 2006;128:9618-9619. [PubMed: 16866501]

47. Corey EJ, Albonico SM, Koelliker U, Schaaf TK, Varma RK. Journal of the American Chemical Society 1971;93:1491-1493. [PubMed: 5548347]

48. Campbell JBJ, Molander GA. J Organomet Chem 1978;156:71-79.

49. Zweifel G, Arzoumanian H. J Am Chem Soc 1967;89:5086-5088.

50. Negishi E, Yoshida T. J Chem Soc, Chem Commun 1973:606-607.

51. Negishi E, Williams RM, Lew G, Yoshida T. J Organomet Chem 1975;92:C4-C6.

52. Brown HC, Imai T, Bhat NG. J Org Chem 1986;51:5277-5282.

53. Leroy J. Organic Syntheses 1997;74:212-216.

54. Murray RE. Synth Commun 1980;10:345-349.

55. Chen YK, Jeon SJ, Walsh PJ, Nugent WA. Org Synth 2005;82:87-92.

56. Nugent WA. J Chem Soc, Chem Commun 1999:1369-1370.

57. Rudolph J, Hermanns N, Bolm C. J Org Chem 2004;69:3997-4000. [PubMed: 15153043]

58. Weber B, Seebach D. Tetrahedron 1994;50:7473-7484.

59. Berrisford DJ, Bolm C, Sharpless KB. Angew Chem, Int Ed 1995;34:1059-1070.

60. Schmidt F, Stemmler RT, Rudolph J, Bolm C. Chem Soc Rev 2006;35:454- 470. [PubMed: 16636728]

61. Kim JG, Walsh PJ. Angew Chem, Int Ed 2006;45:4175-4178.

62. Meyer C, Marek I, Courtemanche G, Normant JF. Tetrahedron 1994;50:11665-11692.

63. Chitsaz S, Pauls J, Neumuller B. Z Naturforsch, B 2001;56:245-248.

64. Hoffmann D, Dorigo A, Schleyer PvR, Reif H, Stalke D, Sheldrick GM, Weiss E, Geissler M. Inorg Chem 1995;34:262-269.

65. Rylander, PN. Catalytic Hydrogenation Over Platinum Metal. Academic Press; New York: 1967. p. 22

66. Freifelder, M. Catalytic Hydrogenation in Organic Synthesis: Procedures and Commentary. John Wiley \& Sons; New York: 1978. p. 184

67. Belen'kii, LI.; Gol'dfarb, YL. In Thiophene and Its Derivatives, The Chemistry of Heterocyclic Compounds. Gronowitz, S., editor. 44. John Wiley \& Son; New York: 1985. p. 465

68. Maxted EB, Evans HC. Journal of the Chemical Society 1937:603-606.

69. Bateman L, Shipley FW. Journal of the Chemical Society 1958:2888-2890.

70. de Sousa PT Jr, Taylor RJK. J Braz Chem Soc 1993;4:64-68.

71. Jeon SJ, Walsh PJ. J Am Chem Soc 2003;125:9544-9545. [PubMed: 12903993]

72. Jeon SJ, Li H, Walsh PJ. J Am Chem Soc 2005;127:16416-16425. [PubMed: 16305227]

73. Larsen AO, White PS, Gagné MR. Inorg Chem 1999;38:4824-4828. [PubMed: 11671212]

74. Miyano S, Lu LDL, Viti SM, Sharpless KB. J Org Chem 1985;50:4350-4360. 

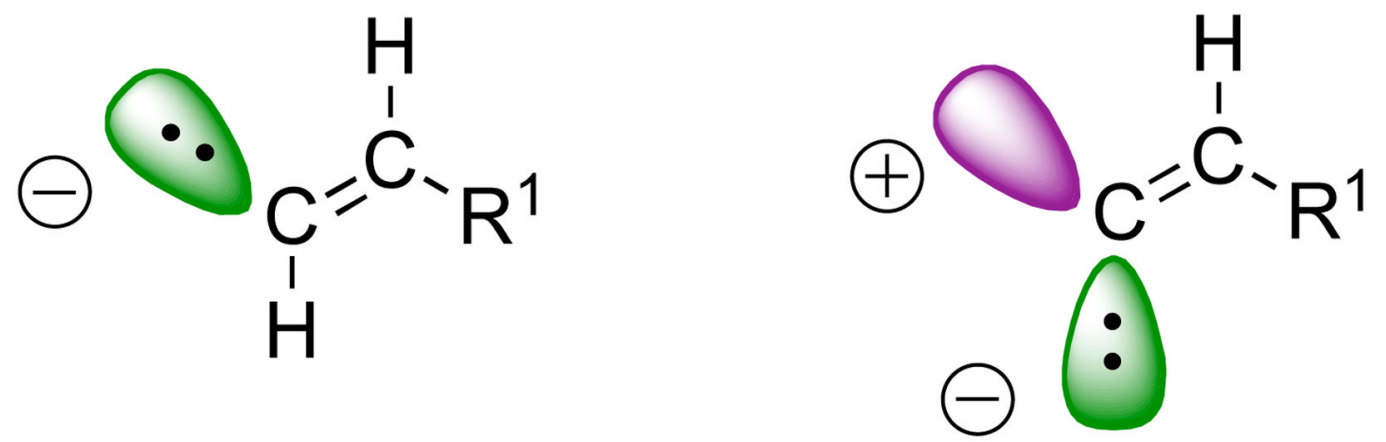

A

B

Figure 1.

Synthon A represents (E)-disubstituted vinyl organometallics while synthon B represents $(Z)$ di- or trisubstituted reagents. 


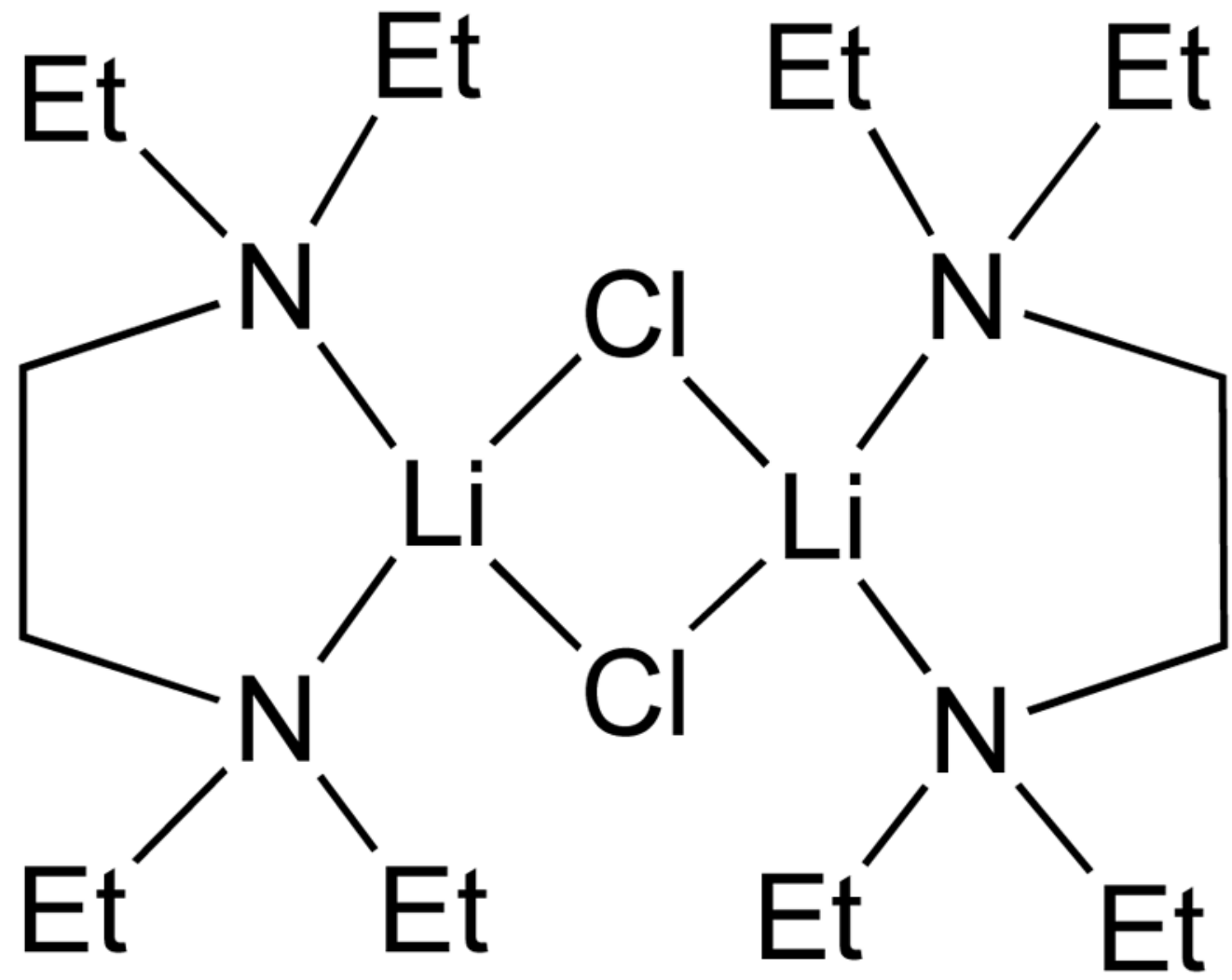

Figure 2.

Possible structure of the coordinatively saturated TEEDA adduct of LiCl. 


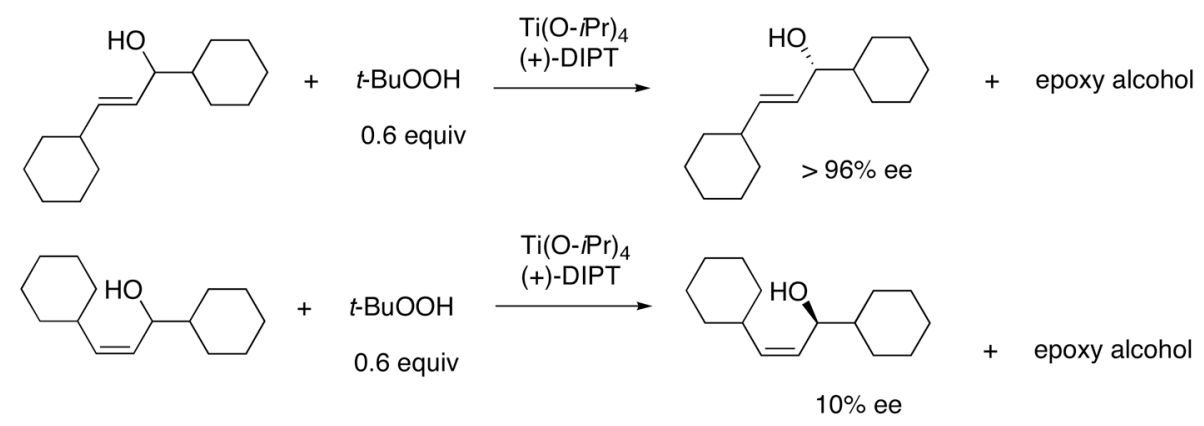

Scheme 1.

Application of the Sharpless-Katsuki Catalyst to the Kinetic Resolution of $(E)$ - and (Z)-Allylic Alcohols. 

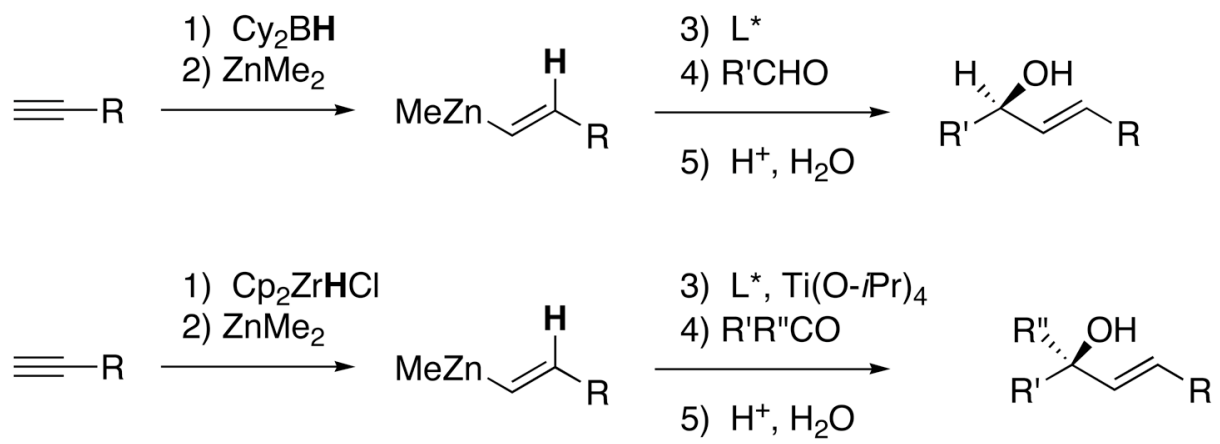

Scheme 2.

Catalytic Asymmetric Vinylation of Aldehydes and Ketones via Hydrometallation of Terminal Alkynes, Transmetallation, and Addition. 


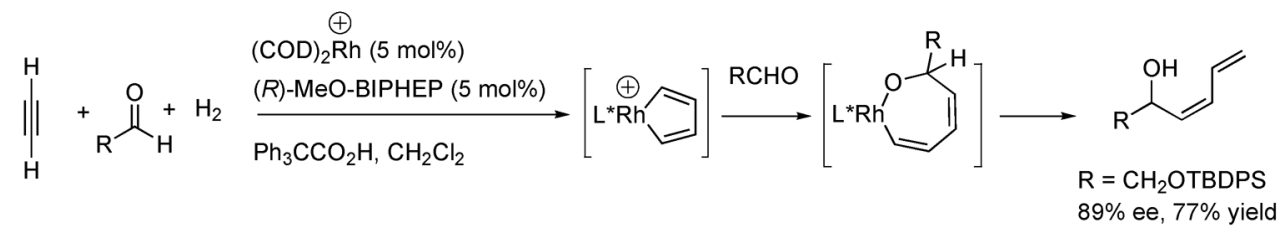

Scheme 3.

Generation of (Z)-Dienyl Alcohols and Proposed Intermediates by Krische and Coworkers. 


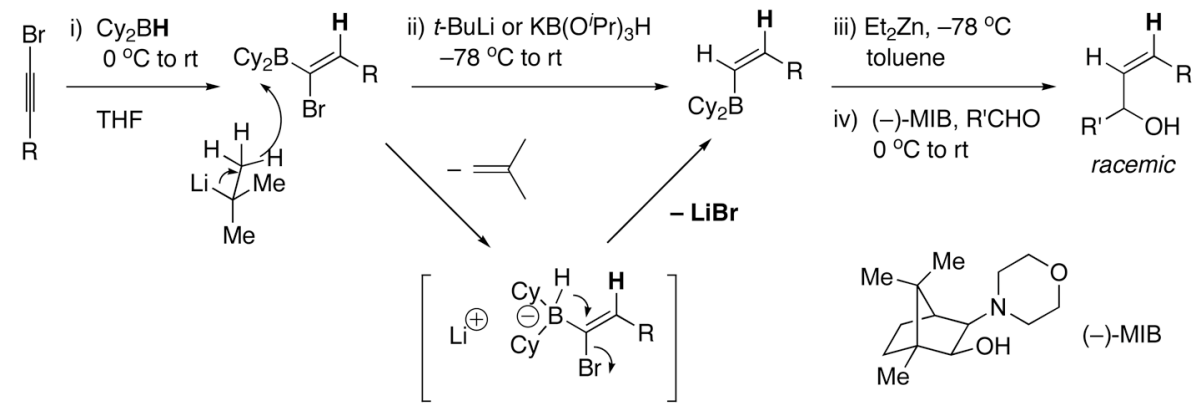

Scheme 4.

Our Stereospecific Method for the Synthesis of (Z)-Allylic Alcohols. 


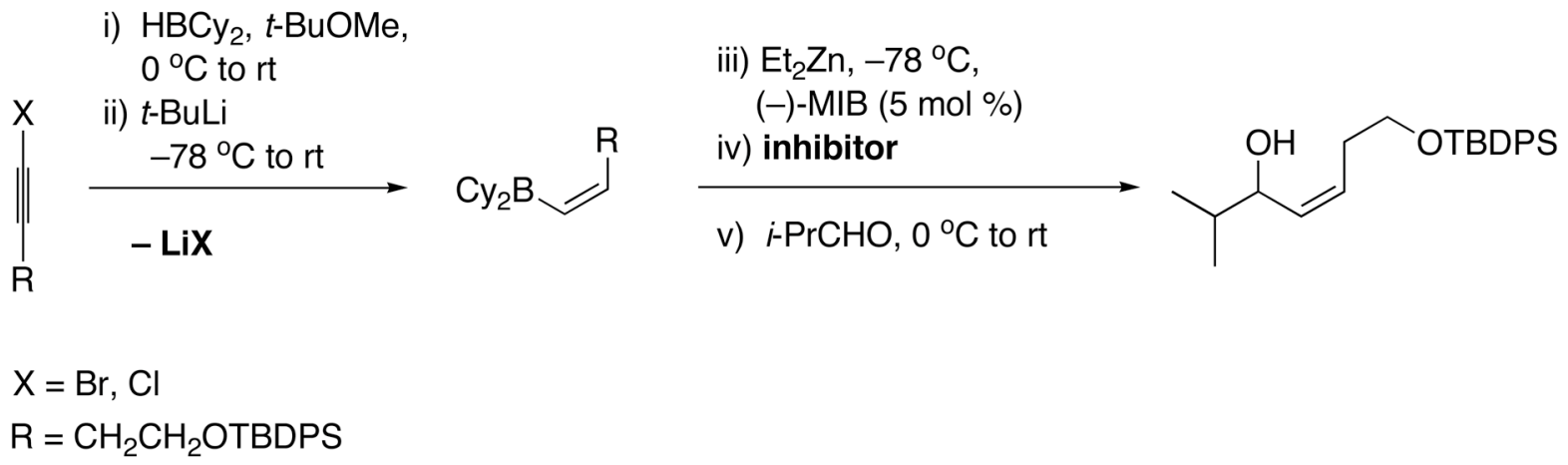

Scheme 5.

Optimization of the Catalytic Asymmetric Generation of (Z)-Allylic Alcohols. 


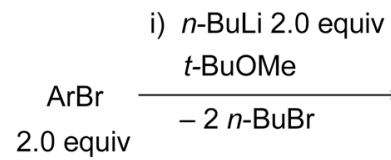
iv) TEEDA (0.8 equiv) Hex or Tol
v) (-)-MIB (5 mol\%)
vi) $\mathrm{R}^{1} \mathrm{CHO}$ (1 equiv)
$0^{\circ} \mathrm{C}$
no TEEDA $2 \%$ ee
TEEDA $>90 \%$ ee

Scheme 6.

Asymmetric Arylation of Aldehydes with TEEDA to Inhibit LiCl. 
i) $\mathrm{HBCy}_{2}, t$-BuOMe $\left(0^{\circ} \mathrm{C}\right)$

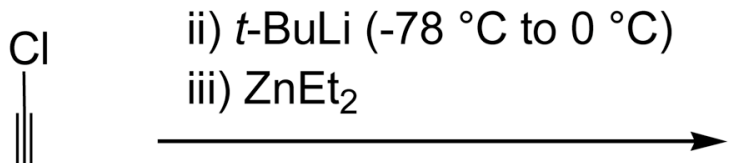

$\mathrm{R}$

1
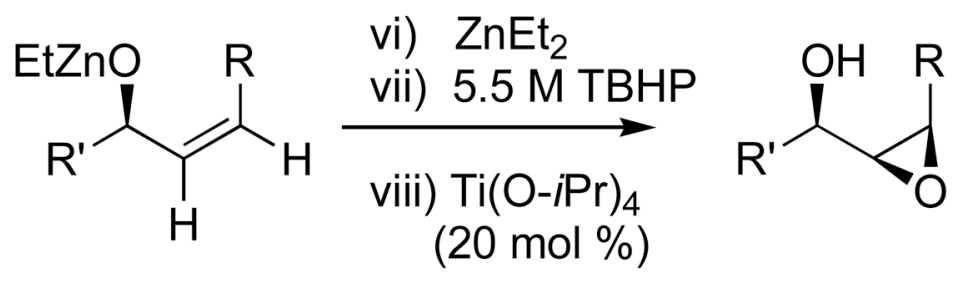

v) (-)-MIB (5 mol \%)

$\mathrm{PhCHO}(2 \mathrm{c}), 0{ }^{\circ} \mathrm{C}$ to $\mathrm{rt}$

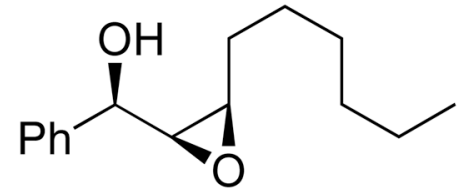

$4 b c$

$$
\begin{aligned}
& 52 \% \text { yield } \\
& 93 \% \text { ee } \\
& 19: 1 \mathrm{dr}
\end{aligned}
$$<smiles>O[C@H](c1ccccc1)C1OC1CCCCCl</smiles>

4cc

$67 \%$ yield

$88 \%$ ee

$19: 1 \mathrm{dr}$
4<smiles>OC(c1ccccc1)[C@H]1OC1c1ccccc1</smiles>

4dc

$59 \%$ yield $97 \%$ ee $19: 1 \mathrm{dr}$

Scheme 7.

Tandem Asymmetric Addition/Diastereoselective Epoxidation. 


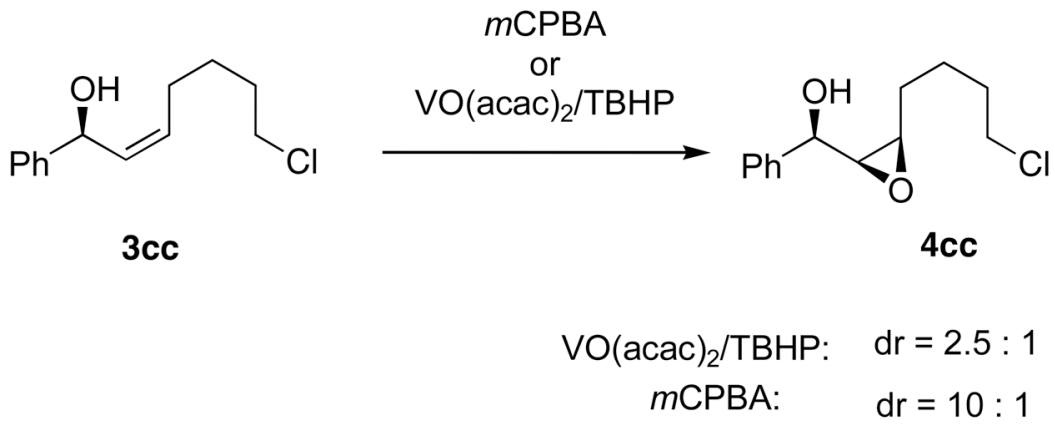

Scheme 8.

Epoxidation of the Isolated Allylic Alcohol with $\mathrm{VO}(\mathrm{acac})_{2} / \mathrm{TBHP}$ and $m \mathrm{CPBA}$. 

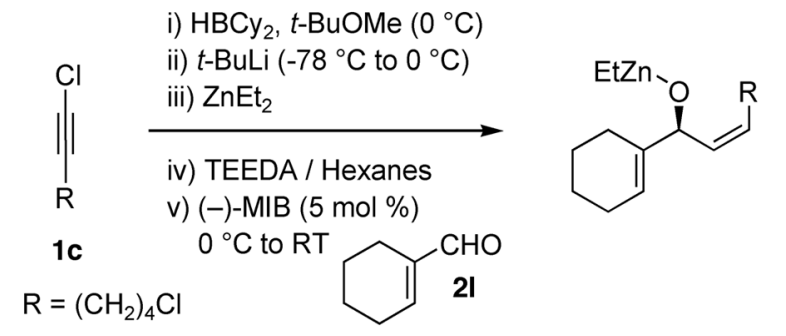

i) $\mathrm{ZnEt}_{2}$

ii) $\mathrm{TBHP}$

$\stackrel{(20 \mathrm{~mol} \mathrm{\%})}{\longrightarrow}$

iii) $\mathrm{Ti}(\mathrm{O}-\mathrm{PPr})_{4}$

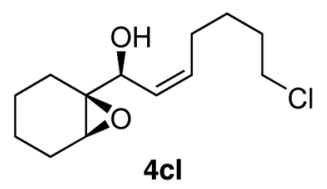

$52 \%$ yield

$94 \%$ ee

$19: 1 \mathrm{dr}$

Scheme 9.

Tandem Asymmetric Addition/Diastereo- and Chemoselective Epoxidation. 


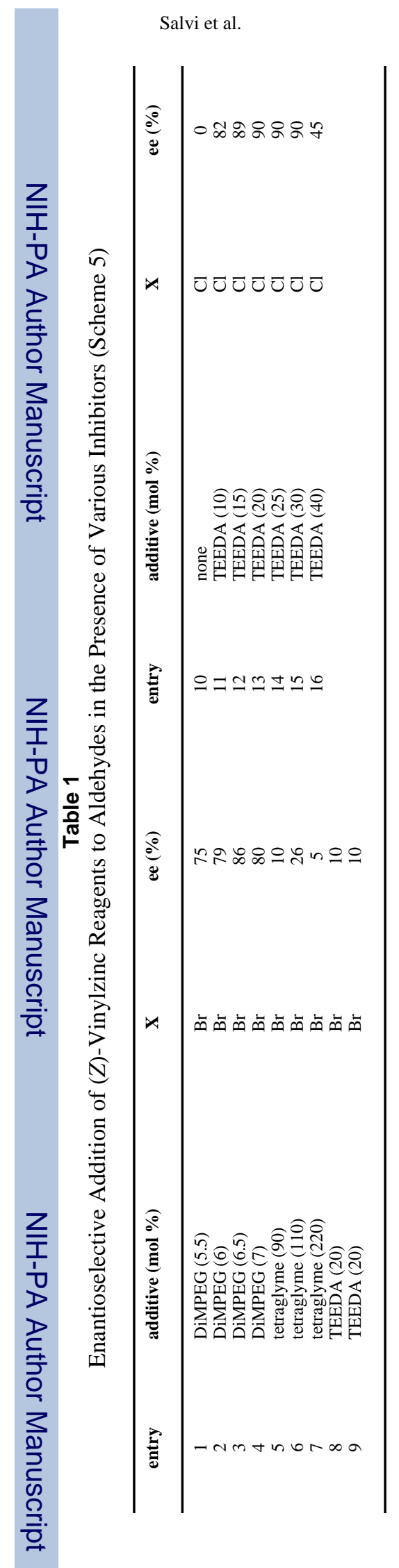

$J$ Am Chem Soc. Author manuscript; available in PMC 2008 December 26. 


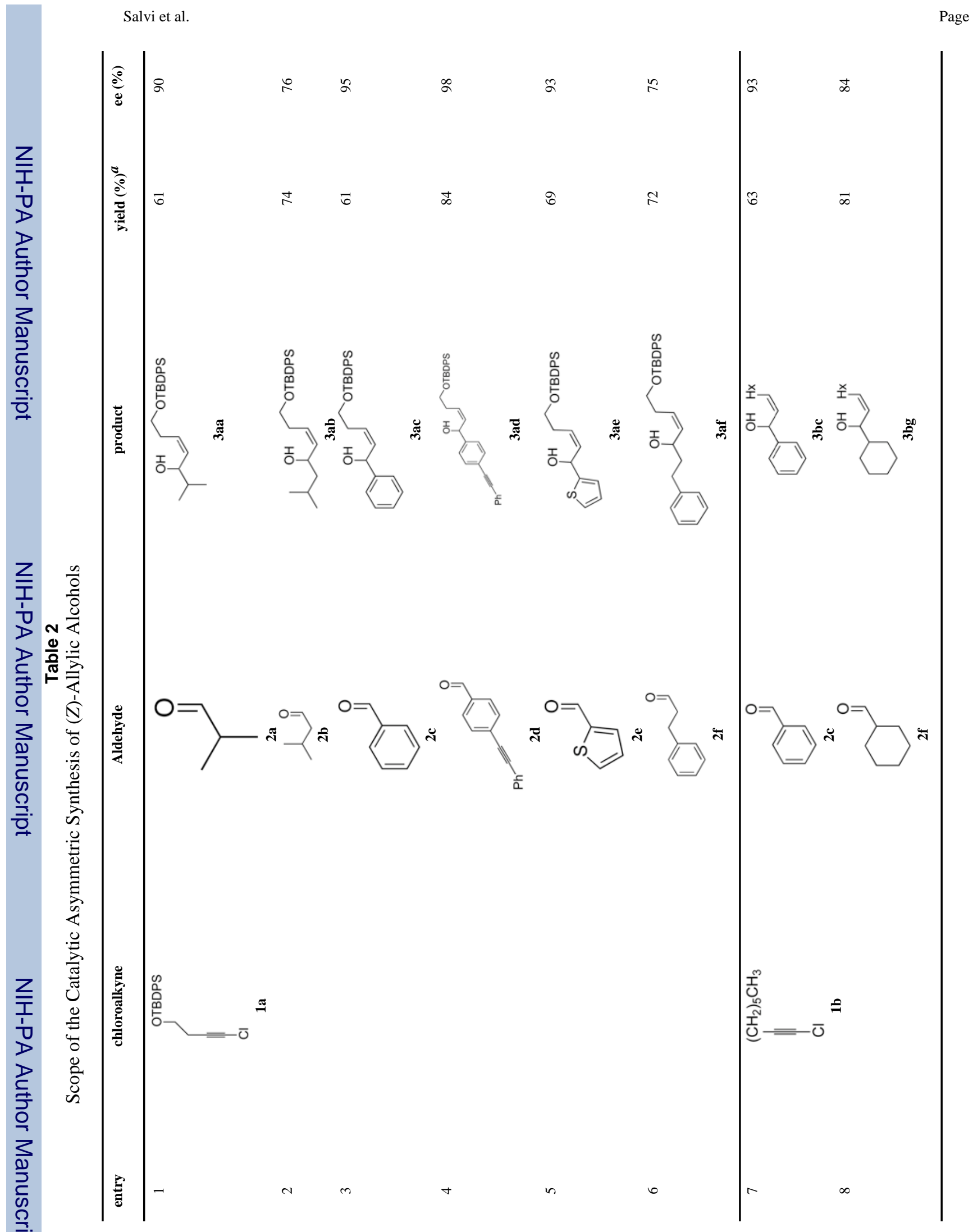

J Am Chem Soc. Author manuscript; available in PMC 2008 December 26. 
Salvi et al.

Page 23

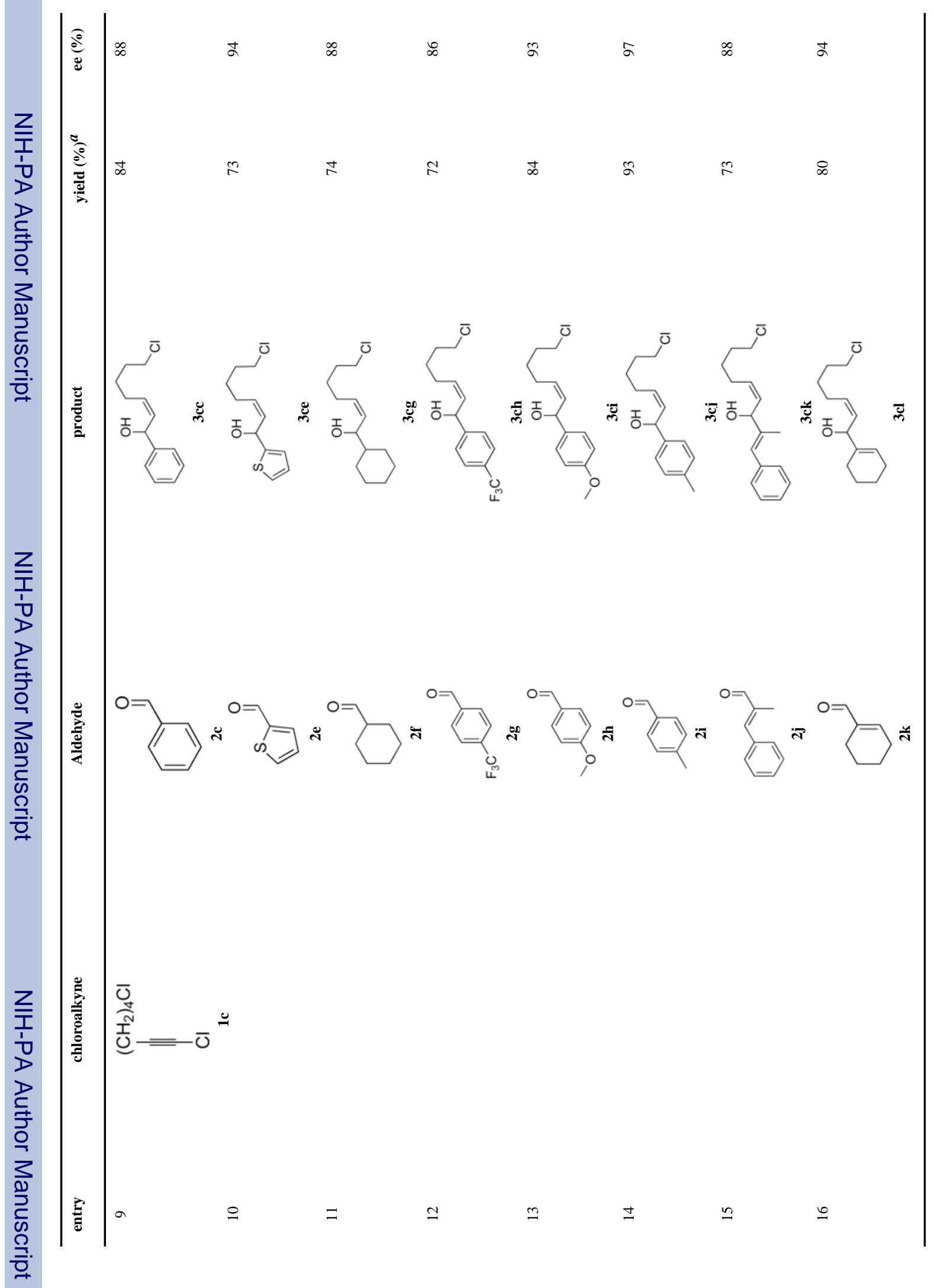

J Am Chem Soc. Author manuscript; available in PMC 2008 December 26. 


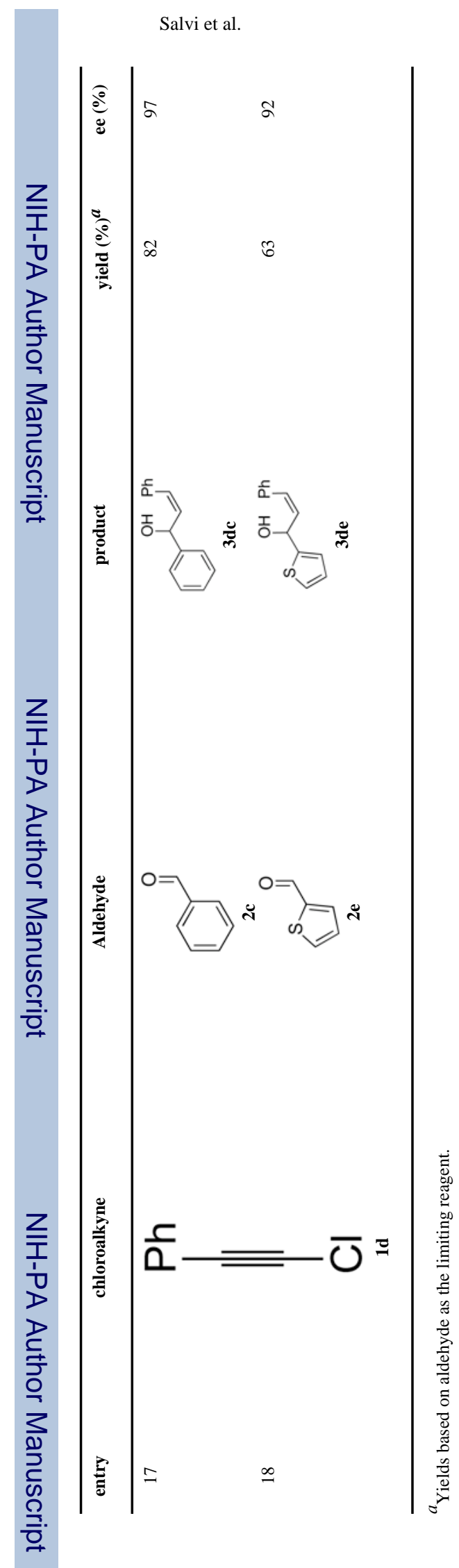

J Am Chem Soc. Author manuscript; available in PMC 2008 December 26. 